\title{
A DINÂMICA POPULACIONAL DAS PEQUENAS CIDADES NO TERRITÓRIO DO SISAL (1990-2014).
}

\author{
TAMIRES DA SILVA BRITO ${ }^{1 ;}$; ONILDO ARAÚJO DA SILVA ${ }^{2}$ \\ 1. Bolsista PIBIC/UEFS, Graduando em Geografia, Universidade Estadual de Feira de Santana, e-mail: \\ tam.tamires10@gmail.com \\ 2. Orientador, Departamento de Ciências Humanas e Filosofia, Universidade Estadual de Feira de Santana, e-mail: \\ fssilvafs@hotmail.com
}

PALAVRAS-CHAVE: Território do Sisal, Dinâmica Populacional, Pequena Cidade.

\section{INTRODUÇÃO}

Nesse trabalho tentamos analisar como a dinâmica populacional influência a organização espacial nas pequenas cidades no Território do Sisal. O Território do Sisal está situado no semiárido do Estado da Bahia, é integrado pelos municípios de Serrinha, Conceição do Coité, Tucano, Santaluz, Araci, Valente, Queimadas, Cansanção, Itiúba, Monte Santo, Retirolândia, Quijingue, São Domingos, Barrocas, Teofilândia, Nordestina, Biritinga, Candeal, Lamarão e Ichu. Cada município traz em sua história a influência Da cadeia produtiva do sisal, essa característica é marcante em todo o Território.

Dos vinte municípios que compõem o Território do Sisal, apenas dois não farão parte da nossa investigação: Conceição do Coité e Serrinha. Ambos não são considerados como pequena cidade, no projeto de investigação ao qual esse plano de trabalho se vincula.

Tentamos também compreender as possíveis transformações decorrente da dinâmica populacional para organização espacial nas pequenas cidades no Território do Sisal.

Depois de caracterizar a dinâmica populacional nas pequenas cidades no Território do Sisal com foco nos dados sobre distribuição da população por faixa etária, situação de domicílio, gênero e mobilidade.

\section{MATERIAL E MÉTODOS OU METODOLOGIA (ou equivalente)}

Para o desenvolvimento dessa investigação realizamos uma revisão de literatura e construímos um referencial teórico. Também foi realizado um levantamento de dados secundários referentes a dinâmica da população, em fontes como o Instituto Brasileiro de Geografia e Estatística (IBGE), Superintendência de Estudos Econômicos e Sociais da Bahia (SEI), Instituto de Pesquisa Econômica Aplicada (IPEA), que compôs a segunda fase do nosso trabalho.

A penúltima etapa da investigação foi a tabulação dos dados secundários que, analisados, resultaram na organização de gráficos, tabelas e pirâmide. Por fim, construímos o relatório final, que é considerado a última etapa do trabalho.

Utilizamos materiais como computadores/notebook, máquina fotográfica/filmadora, gravador, impressora, cartuchos preto/colorido, papel comum A4, pastas, grampeador, clip, entre outros materiais de escritório. 


\section{RESULTADOS E/OU DISCUSSÃO (ou Análise e discussão dos resultados) Dinâmica populacional dos Municípios do Território do Sisal}

Com o objetivo de caracterizar a dinâmica populacional e analisar como a mesma influência a organização espacial nas pequenas cidades no Território do Sisal, começaremos nossa análise, dando foco para os dados de distribuição populacional por faixa etária, situação de domicílio, gênero e mobilidade.

Inicialmente fizemos uma pequena analise sobre a polução residente na sede dos municípios foco da nossa pesquisa, tentando sistematizar dados sobre distribuição da população residente na sede (gráfico 1). De acordo com o gráfico, podemos observar um crescimento do contingente populacional urbano em todos os municípios recorte temporal para a nossa análise (1991-2010), exceto em Ichu e Lamarão. Vale ressaltar que não encontramos dados referentes ao município de Barrocas para os censos de 1991 e 2000, uma vez que o mesmo ainda não era emancipado e fazia parte do município de Serrinha (Lei Estadual n n $^{\circ} 620$ cria o município de Barrocas no ano de 2000).



Fazendo uma pequena análise sobre a distribuição da população urbana por gênero,tendo como recorte temporal o senso de 2010, observamos no gráfico 2 que em todos os municípios analizados há uma predominancia do sexo feminino em relação ao masculino 




Também realizamos uma análise sobre a pirâmide etária de cada município. A pirâmide etária populacional nada mais é do que um gráfico utilizado para expressar os dados referentes à quantificação populacional e grupos de idade, de modo a permitir uma melhor visualização da distribuição da população em função da idade.

Analisando em conjunto as pirâmides dos municípios envolvidos nesse estudo, podemos dizer que a maioria mantem uma base larga, o que indica ainda significativas taxas de natalidade. 


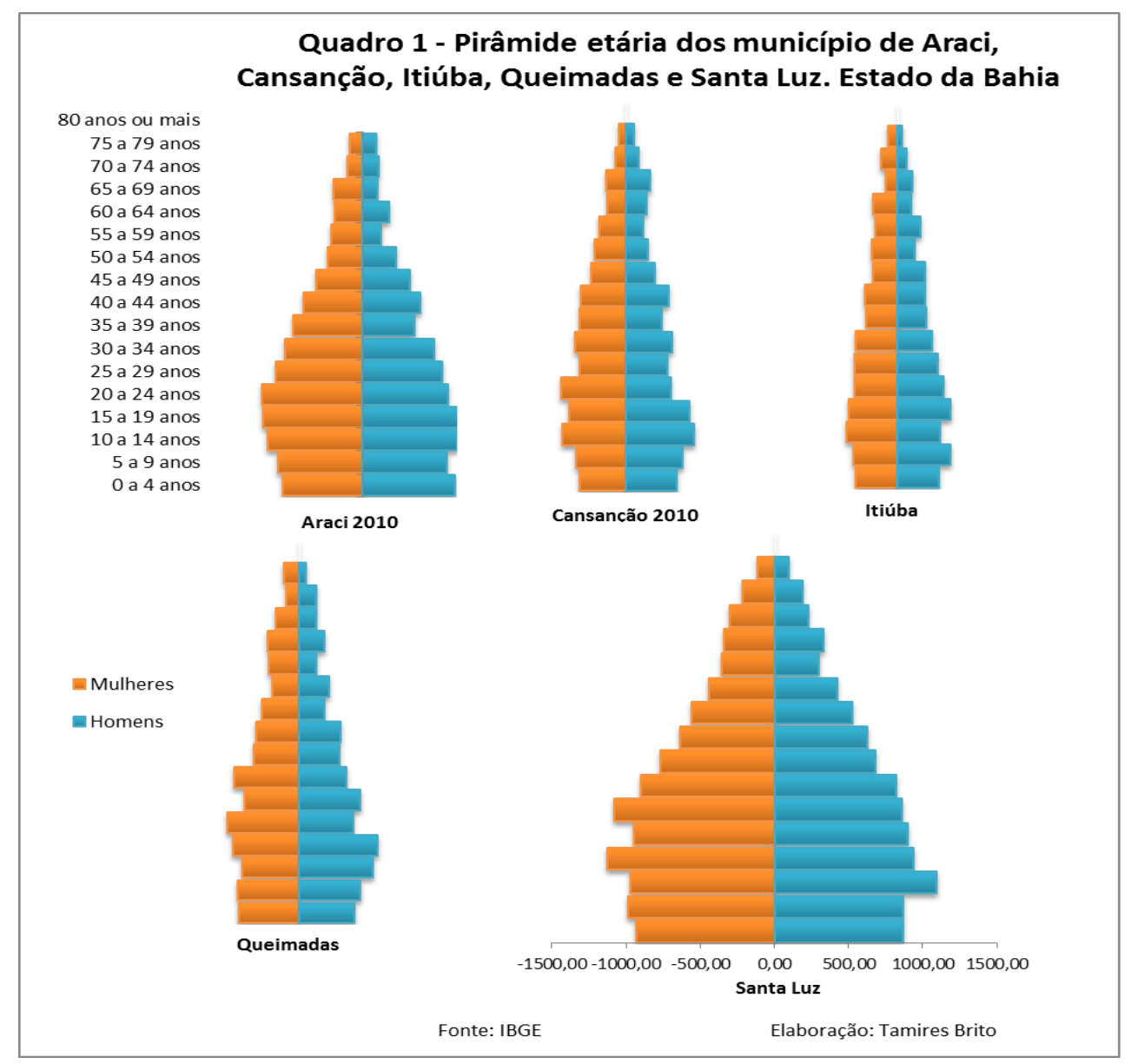

Como podemos observar no quadro 1 os municípios de Araci, Cansação, Itiúba, Queimadas e Santa Luz possuem pirâmides que indicam aindfa uma base larga, permitindo inferir que necessitaram de investimentos direcionados em saúde, educação, lazer, qualificação profissional, geração de emprego e renda.

\section{CONSIDERAÇÕES FINAIS (ou Conclusão)}

Concluímos que praticamente todos os municípios do Território do Sisal possuem pirâmide etária de base larga, tendo como recorte temporal o censo de 2010. O que acarreta em maior demanda em investimentos direcionados para educação, lazer, qualificação profissional, emprego e geração de renda.

A maioria dos municípios apresenta um crescimento urbano (gráfico 1) considerável, com exceção de Ichu e Lamarão. Esses dois municípios demonstram uma perda em seu contingente populacional urbano entro do recorte temporal analisado do trabalho que foi de 1991-2010. O que chama atenção também é que nos municípios do Território do Sisal analisados na pesquisa, há uma predominância do sexo feminino em relação ao masculino (gráfico 2).

\section{REFERÊNCIAS}

DAMIANI, Amélia Luisa. População e geografia, 2º ed. São Paulo, 1996. RIOS-NETO, Eduardo Luiz Gonçalvez. Questões emergentes na análise demográfica: o caso brasileiro. Revista brasileira Est. Pop., São Paulo, v. 22, n. 2, p. 371-408, jul./dez. 2005

IBGE - Instituto Brasileiro de Geografia e Estatística. Disponível: http://www.ibge.gov.br/home/ Acessado em 15/02/2017 